\title{
Antimicrobial activity of chitosan and its derivatives exhausted cotton fabrics as ecofriendly antimicrobial
} \section{agents}

\begin{abstract}
Development of the antimicrobial activity of cotton fabric using chitosan, N-(2-Hydroxy) propyl-3- trimethyl-ammonium chitosan chloride (HTACC), and N-methylol-acrylamideN-(2-hydroxy) propyl-3-trimethyl-ammonium chitosan chloride (NMA-HTACC) was investigated. Moisture absorbency is an important property of cotton fabric due to which bacteria can easily affect the cotton fabric and lowers the quality of it. Chitosan, HTACC, and NMA-HTACC were applied on cotton fabric by exhaustion method and observed antibacterial activity against Escherichia coli and Staphylococcus aureus. Among the finished fabrics, NMA-HTCC treated cotton fabric showed over $93 \%$ of bacterial reduction against $E$. coli and over $97 \%$ of bacterial reduction against $S$. aureus even after 30 home launderings. This is due to the strong attachment ability of NMA-HTACC to cotton fabric and better solubility in aqueous solution and the presence of positive charge of the nitrogen atom in its structure in all conditions. For this reason, NMA-HTACC can be applied to develop cotton fabric as anti-bacterially active which makes it suitable for medical purposes by minimizing the chances of growth and multiplication of bacteria.
\end{abstract}

Volume 6 Issue 3 - 2020

\author{
Md Ibrahim H Mondal, Firoz Ahmed, Md \\ Roknuzzaman, Md Nazmul Huda, Md Ahsan \\ Habib \\ Polymer and Textile Research Lab, Department of Applied \\ Chemistry and Chemical Engineering, Rajshahi University, \\ Bangladesh
}

Correspondence: Md Ibrahim H Mondal, Polymer and Textile Research Lab, Department of Applied Chemistry and Chemical Engineering, Rajshahi University, Rajshahi-6205, Bangladesh, Tel +880-72I-7I I629, Fax +880-72I-7III 3 I,

Emailmihmondal@gmail.com

Received: April 10, 2020 | Published: May 22, 2020

Keywords: chitosan, antimicrobial activity, cotton fabric, chitosan derivatives

\section{Introduction}

Biodegradability, renewability, moisture absorbency, comfortability etc of natural cellulose-based cotton fabric make it more suitable for different purposes especially healthcare as well as medical purposes than any other fabrics. Also due to having no environmental impact its demand is increasing day by day. Besides these cellulose-based cotton fabric possess an important inherent limitation is microbial attack which limits the direct use of it in medical sector. ${ }^{1}$ To minimize the microbial degradation and to improve the textile properties many researchers finished the cotton fabric with different chemical agents such as triclosan, metal and their salts, phenols and organo metallics etc. which show good antimicrobial activity on cotton fabric but have a great concern for both environment and human health. That's why an ideal anti-microbial textile finishing agent need to be safe, non-toxic, environmentally benign and durable to wash, so textile researchers should prefer to apply eco-friendly finishing agents on cotton fabrics. Chitosan and its water soluble derivatives such as $\mathrm{N}$-(2-Hydroxy) propyl-3-trimethylammonium chitosan chloride (HTACC) and N-methylolacryl amide-N-(2-hydroxy) propyl-3-trimethylammonium chitosan chloride (NMA-HTACC) have a positive charged nitrogen atom in its structure which has a possibility to damage the negatively charged bacterial cell wall. ${ }^{2}$ Hence, the major objectives of this study are to:

1) Develop the antibacterial activity of the finished cotton fabric with chitosan and its derivatives (HTACC and NMA-HTACC)

2) Compare the antibacterial activity of Chitosan, HTACC and NMA-HTACC finished cotton fabrics

3) Manage the prawn shell waste through a value-added product in textile finishing.

\section{Experimental}

\section{Materials}

Prawn shell was collected from Mongla (near Sundarban forest), Khulna, Bangladesh. Cotton fabrics were collected from Keya Spinning Mills Ltd., Bangladesh. Escherichia coli and Staphylococcus aureus bacteria are collected from "Biochemistry and Molecular Biology" department of Rajshahi University. Hydrochloric acid, sodium hydroxide, acetone, methanol etc. were purchased from Sigma Aldrich, Merck, BDH etc and used without further purification.

\section{Methods}

Fabric preparation: Cotton fabrics were washed with $0.2 \% \mathrm{Na}_{2} \mathrm{CO}_{3}$ solution at $75^{\circ} \mathrm{C}$ for $30 \mathrm{~min}$ in a beaker in the fabric to liquor ratio of 1:50. After washing thoroughly with distilled water and drying at $60^{\circ} \mathrm{C}$, the fabric was stored in a desiccators. ${ }^{3}$

Finishing process: First, HTACC, NMA-HTACC were dissolved in distilled water and whereas chitosan was dissolved in $2 \%(\mathrm{v} / \mathrm{v})$ aqueous acetic acid solution (maintaining $\mathrm{pH}-5.5$ ) by stirring for 2-3 $\mathrm{h}$ and sonicated for $2 \mathrm{~h}$. Then $50 \mu \mathrm{L}$ of Triton- $\mathrm{X}$ was added to the liquor to improve the wettability. ${ }^{4,5}$

In Exhaustion method, the fabrics were immersed in the prepared solution of various concentrations and were sonicated for $1 \mathrm{hr}$ at $70^{\circ} \mathrm{C}$. The samples were then dried at $100^{\circ} \mathrm{C}$ for $10 \mathrm{~min}$ and cured at $170^{\circ} \mathrm{C}$ for $5 \mathrm{~min}$. These treated cotton fabrics were dried at an ambient condition. $^{6}$

\section{Characterization of finished fabrics}

Moisture absorption study: The finished and washed cotton fabrics were placed on a humidity chamber at room temperature $\left(70^{\circ} \mathrm{C}\right)$ 
for a week where humidity was maintained at the saturation level. After that the fabrics were analyzed by moisture analyzer using the following formula:

$$
\text { Moisture Content, }(\%)=\frac{\text { wf-wi }}{\text { wi }} \times 100
$$

Where $W_{f}$ is the weight of wet sample and $W_{i}$ is the weight of dry sample.

Swelling behavior study: Swelling behaviour of the finished and washed cotton fabric were determined by dipping into water at room temperature for $24 \mathrm{~h}$. The percent swelling was calculated according to following equation. ${ }^{8}$

$$
\text { Percent Swelling, }(\text { Ps })=\frac{\text { wf-wi }}{\text { wi }} \times 100
$$

Where $W_{i}$ is the initial weight of fabric and $W_{f}$ is the final weight of fabric.

\section{Water vapor permeability test}

The water vapour permeability of the samples was measured using the cup method, according to ASTM E96 (procedure B) testing standard. The water vapour permeability of the finished and nonfinished fabrics can be calculated by the following equation:

$$
\mathrm{WVP}=\frac{24 \times \mathrm{M}}{A \times T} g / m^{2} / 24 h
$$

Where, $\mathrm{M}$ is the loss in mass of water $(\mathrm{g})$; $\mathrm{T}$, the time interval (h); and $\mathrm{A}$, the internal area of the cup $\left(\mathrm{m}^{2}\right)$. A was calculated using the following relationship, ${ }^{8}$ :

$$
A=\frac{\pi d 2}{4} \times 10^{-4}
$$

Where $\mathrm{d}$ is the internal diameter of the cup ( $\mathrm{mm})$.

\section{Assessment of antibacterial activity (quantitative test)}

Bacterial percent reduction was calculated using the following formula.

$$
\mathrm{R}=(\mathrm{A}-\mathrm{B}) / \mathrm{A} \times 100 \%
$$

Where $R$ is percentage reduction, $A$ is the number of bacteria in the broth inoculated with treated test fabric sample immediately after inoculation i.e., at zero contact time and $B$ is the number of bacteria recovered from the broth inoculated with treated test fabric sample after the desire contact period (18 hours).

\section{Fourier transform infrared (FTIR) analysis}

FTIR spectroscopic measurements were carried out in Central Science Laboratory, University of Rajshahi, Bangladesh (Shimadzu-8900, FTIR Spectrum, Kyoto, Japan). Samples were placed in the path of infrared beam of wave number in the range of $400-4000 \mathrm{~cm}^{-1}$.

\section{Scanning electron microscopy (sem) analysis}

Scanning electron microscopic (SEM) studies of raw and finished cotton fabrics were carried out on an Electron Microscopy Machine (FEI Quanta Inspect, Model:S50).

\section{Thermal analysis}

Thermo gravimetric Analysis (TGA) was performed using a Perkin Elmer simultaneous thermal analyzer (STA 8000, Germany). The tests were conducted between $30-600^{\circ} \mathrm{C}$ under an inert atmosphere (Nitrogen). The heating rate and the airflow rate were $20^{\circ} \mathrm{C} / \mathrm{min}$ and $200 \mathrm{ml} / \mathrm{min}$ respectively.

\section{Results and discussion}

Moisture absorption, swelling test, WVP test, tensile strength, \% elongation, wash fastness and biodegradation reports of washed and finished cotton fabrics are shown in Table 1. From the Table, finished cotton fabrics showed improved physicochemical properties. Due to the presence of hydroxyl groups (-OH) and channel-like structure finished fabric showed better moisture absorption. Also for having the good attachment capacity on cotton fabric, NMA-HTACC treated cotton fabric shows higher moisture absorption. ${ }^{7}$ Similarly, in case of swelling test, swelling of control fabric was lower than others because of lacking the cross-linked channel structure to hold water for being swollen. In terms of WVP test, after applying Chitosan, HTACC, and NMA-HTACC on cotton fabric hydrophilic properties were aroused and channel-like structures are formed which attract water vapour and help to pass away to the outer side of the fabric to saturate the outer side. Due to more fibre reactivity, NMA-HTACC finished fabric showed higher WVP test value. Fabrics used for wound dressing

\begin{tabular}{|c|c|c|c|c|c|c|c|}
\hline Fabric type & $\begin{array}{l}\text { Moisture } \\
\text { absorption } \\
\text { (\%) }\end{array}$ & $\begin{array}{l}\text { Swelling } \\
(\%)\end{array}$ & $\begin{array}{l}\text { Water vapor } \\
\text { permeability } \\
\left(\mathrm{g} / \mathrm{m}^{2} / \mathrm{day}\right)\end{array}$ & $\begin{array}{l}\text { Tensile } \\
\text { Strength } \\
\text { (N) }\end{array}$ & $\begin{array}{l}\% \\
\text { Elongation }\end{array}$ & $\begin{array}{l}\text { Wash fastness } \\
\text { (\% reduction at } \\
25^{\text {th }} \text { wash) }\end{array}$ & $\begin{array}{l}\text { Biodegradation } \\
\text { (\% wt loss at } \mathbf{2 8}^{\text {th }} \\
\text { day) }\end{array}$ \\
\hline Control & 17.4 & 118.6 & $137 \mid .3$ & 290 & 9 & Nil & 78 \\
\hline Chitosan Finished & 25.7 & 162.8 & 843.1 & 325 & 10 & Nil & 30 \\
\hline HTACC Finished & 29.6 & 198.5 & 857.6 & 362 & 10.5 & 56 & II \\
\hline NMA-HTACC Finished & 32.5 & 210.7 & 883.5 & 375 & 10.75 & 78 & 8 \\
\hline
\end{tabular}
should have neither higher nor lower WVP value. So for this NMAHTACC treated cotton fabrics will be more suitable to provide moist wound condition. ${ }^{10}$

Table I Physico-chemical tests of control and finished cotton fabric 


\section{FTIR analyses}

The FTIR spectra of washed and finished cotton fabrics are represented in Figure 1. FTIR spectra of washed and finished fabrics were nearly the same except the appearance of some new peaks on the finished fabric. The appearance of the peak at $1600 \mathrm{~cm}^{-1}$ for $\mathrm{N}-\mathrm{H}$ bending of the primary amine (Figure $1 \mathrm{~b}$ ), $1480 \mathrm{~cm}^{-1}$ for $\mathrm{C}-\mathrm{H}$ bending of trimethyl ammonium group (Figure 1c) and $1547 \mathrm{~cm}^{-1}$ for $\mathrm{N}-\mathrm{H}$ bending of the secondary amide in the acrylamidomethyl group (Figure 1d) which confirm the attachment of chitosan, HTACC and NMA-HTACC on cotton fabric respectively.

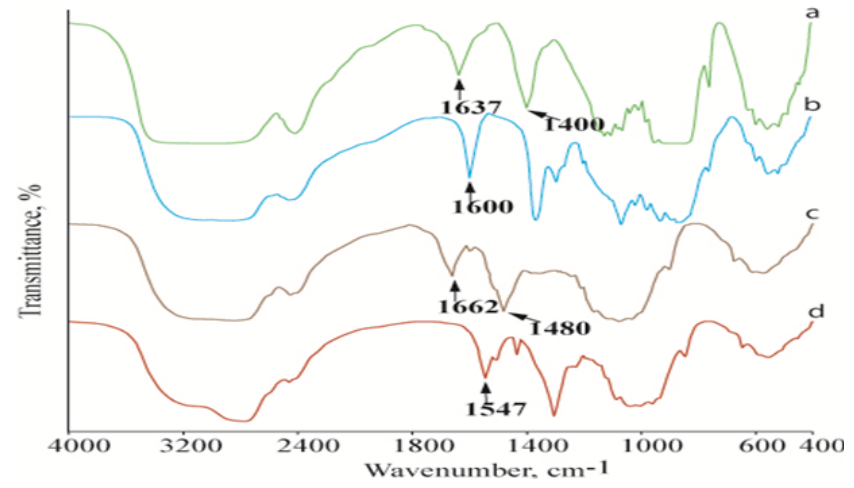

Figure I FITR spectra of a) washed, b) Chitosan finished, c) HTACC finished and d) NMA-HTACC finished cotton fabrics.

\section{Thermal analysis}

Figure 2 shows the thermal behaviour of washed and finished cotton fabrics. According to TGA thermograms, cotton fabrics undergo three stages of thermal degradation. There is a weight loss in the first stage between $90-120^{\circ} \mathrm{C}$, due to dehydration. In the second stage between $280-340^{\circ} \mathrm{C}$, rapid weight losses are observed for thermal degradation of the glycoside linkage and last stage, residual char is formed through weight loss which reaches to be a fixed weight. On the basis of initial decomposition temperature $\left(\mathrm{T}_{\mathrm{i}}\right)$, the thermal stability of washed and finished cotton fabrics show the following order: washed $<$ Chitosan finished $<$ HTACC finished $<$ NMA-HTACC finished cotton fabrics.
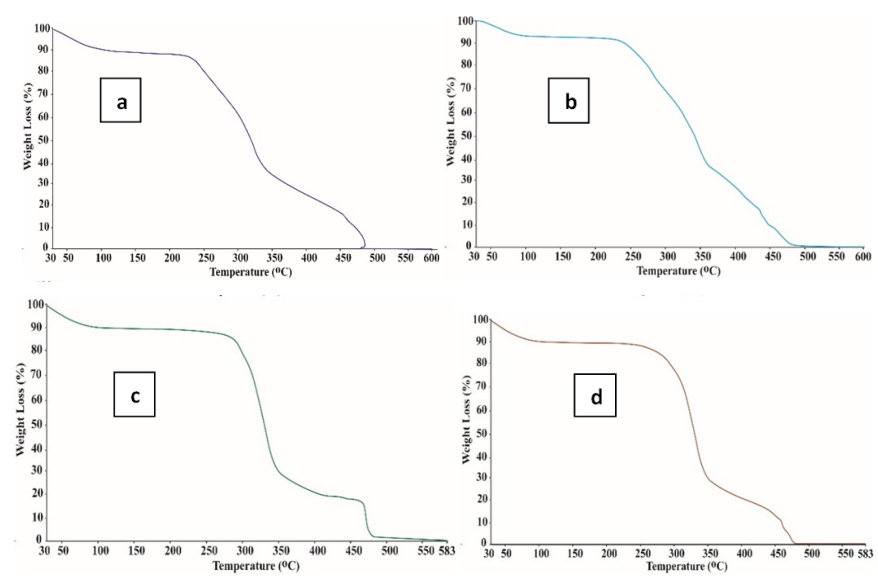

Figure 2 TGA of a) Control, b) Chitosan finished, c) HTACC finished and d) NMA-HTACC finished cotton fabrics.

\section{Surface morphology}

Surface morphology of washed and finished cotton fabrics was studied by Scanning Electron Micrographs. Figures 3b-3c) confirm the attachment of chitosan, HTACC and NMA-HTACC on cotton fabric in comparison with washed fabric (Figure 3a). Among the finished fabrics, SEM of NMA-HTACC finished cotton fabric shows the better attachment of it on cotton fabrics, this is due to having good fibre reactivity.

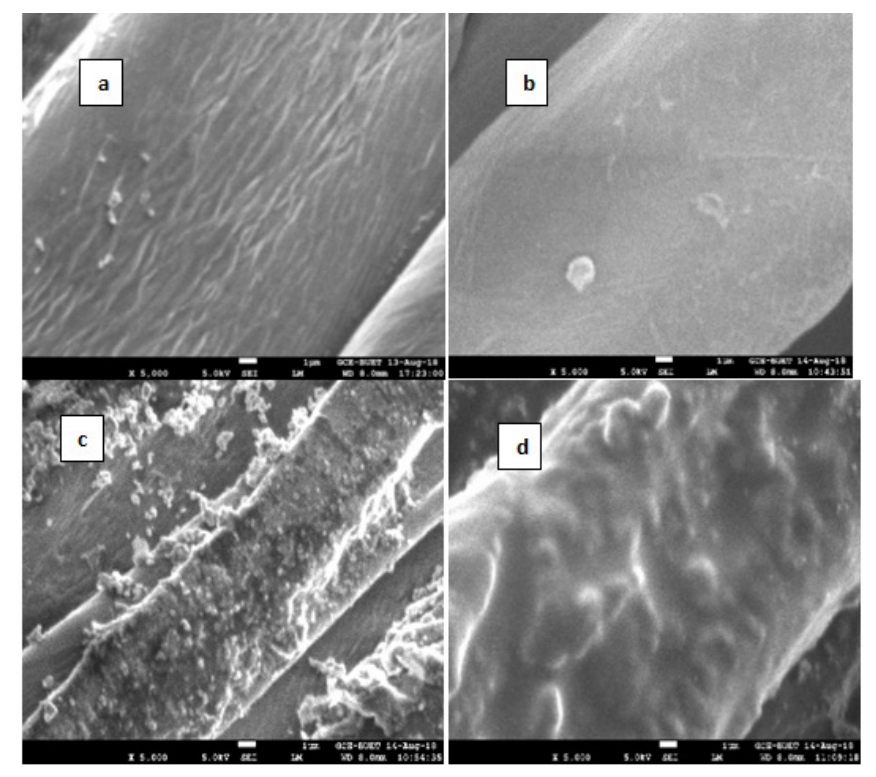

Figure 3 SEM of (a) Control, (b) Chitosan finished, (c) HTACC finished and (d) NMA-HTACC finished cotton fabrics.

\section{Anti-bacterial activity measurement}

Figure 4 represents the anti-bacterial activity test (Quantitative analysis) of finished cotton fabrics. From this Figure, it can be seen that finished cotton fabrics have enough percentage of bacterial reduction against $E$. coli and $S$. aureus. But among these, NMA-HTACC treated cotton fabric shows higher anti-bacterial activity with respect to the percentage of bacterial reduction (97.8\% against $S$. aureus and $93.7 \%$ against $E$. coli) than HTACC and Chitosan treated cotton fabrics. This is due to the better crosslinking activity of NMA-HTACC with cotton fabric than HTACC and Chitosan.

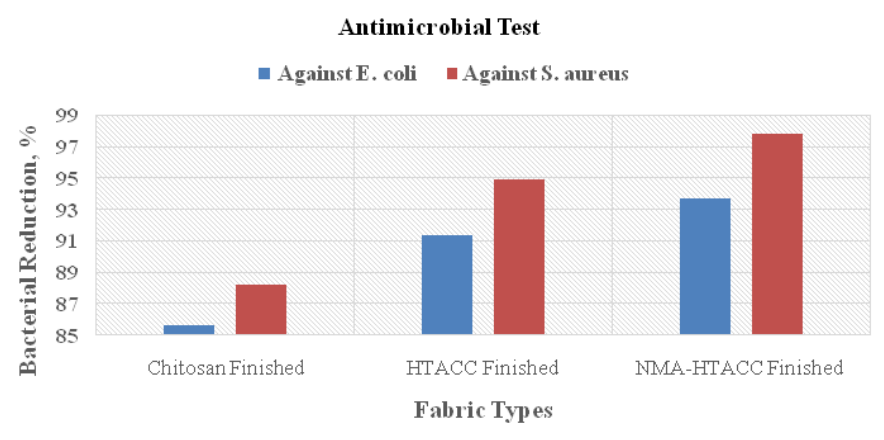

Figure 4 Bacterial reduction (\%) of the finished cotton fabric against $E$. coli and S. aureus.

\section{Conclusion}

In this study Chitosan, HTACC and NMA-HTACC were exhausted on cotton fabric to develop antibacterial property including other textile properties. The presence of the finishing agents on cotton fabrics was confirmed by FTIR and SEM analysis of finished cotton fabrics. The experimental data support that HTACC and NMA- 
HTACC can be used for cotton fabric finishing as an eco-friendly antibacterial agent to make it suitable in medical as well as personal care textiles for both gram-positive and gram-negative bacteria.

\section{Acknowledgments}

None.

\section{Funding}

The authors would like to acknowledge the Faculty of Engineering, Rajshahi University, Bangladesh for funding the Project Ref. No.: 1043/5/52/RU/Eng/2/18-19/83.

\section{Conflicts of interest}

The authors declare there are no conflicts of interest.

\section{References}

1. Ahmed F, Mondal MIH. Preparation and characterization of functionalized chitosan derivatives from prawn waste for cellulose fibre modification to enhance textile properties. Journal of Textile Science \& Engineering. 2017:7(5).

2. Kong M, ChenXG, Xing K, et al. Antimicrobial properties of chitosan and mode of action: A state of the art review. International Journal of Food Microbiology. 2010;144(1):51-63.
3. Farouqui FI, Mondal MIH. Scouring and bleaching of jute fibre in relation to its strength. Rajshahi University Studies. 1989;Part-B, XVII:1-8.

4. Singha AS, Thakur VK. Synthesis and characterization of silane treated grewiaoptiva fibres. International Journal of Polymer Analysis and Characterization. 2009;14(4):301-321.

5. Farouk A, Moussa S, Ulbricht $\mathrm{M}$, et al. $\mathrm{ZnO}$ nanoparticles-chitosan composite as antibacterial finish for textiles. International Journal of Carbohydrate Chemistry. 2012. 8 p.

6. Abd Elhady MM. Preparation and characterization of chitosan/zinc oxide nanoparticles for imparting antimicrobial and UV protection to cotton fabric. International Journal of Carbohydrate Chemistry. 2012. 6 p.

7. Abbasipour M, Mirjalili M, Khajavi R, et al. Coated cotton gauze with $\mathrm{Ag} / \mathrm{ZnO} /$ chitosan nanocomposite as a modern wound dressing. Journal of Engineered Fibers and Fabrics. 2014;9(1):124-130.

8. Das S, Kothari VK. Moisture vapor transmission behaviour of cotton fabrics. Indian Journal of Fibre and Textile Research. 2012;37:151-156.

9. Rajendran R, Balakumar C, Ahammed HAM, et al. Use of zinc oxide nano particles for production of antimicrobial textiles. International Journal of Engineering, Science and Technology. 2010;2(1):202-208.

10. Nawalakhe R, Shi Q, Vitchuli N, et al. Novel atmospheric plasma enhanced chitosan nanofiber/gauze composite wound dressings. Journal of Applied Polymer Science. 2013:129(2):916-923. 